\title{
THE STATUS OF ORCHID CONSERVATION IN CHINA
}

\author{
JIA JIANSHENG \\ Deputy Director \\ Department of Wildlife Conservation, State Forestry Adminstration \\ 18 Hepingli Dongjie, Beijing 100714, P. R. China \\ jiajiansheng@forestry.gov.cn
}

KEY WORDS: ecosystem types, endemic group, conservation, natural reserves, orchid flora, biological characters.

Orchids are a flag group in plant conservation. China has not a rich orchid flora, with only about 1200 specie in about 170 genera, but it is distinguished by having a wider range of broad ecosystem types. On orchid vegetative morphology, a feature reflecting environmental conditions, China has equal numbers of terrestrial and epiphytic (including lithophytic) genera. This feature is quite different from the tropical zone where epiphytic orchids are majority and from the temperate regions where terrestrial orchids predominate, and is unique in the world orchids flora. Of the Chinese orchid flora, there are 502 species in 98 genera being endemic to China, and 26 genera in which have more than half of the total species being endemic to China. Moreover, there are some world famous ornamental or medicinal orchids in China, such as Paphiopedilum, Cypripedium, Cymbidium, Pleione, Holcoglossum and Dendrobium. And the Chinese Cymbidiums are among the best of the favorable ornamental orchids in China. Some Cymbidium plantations, as well as much more private yards, have been set up in China mainland, Taiwan and Hong Kong. Many species of Cymbidium, thus, have become seriously endangered or quite rare or even extinct in some areas.

Recently years, Chinese Government has paid great attention to orchid conservation. General policies have been carried out and some efforts have been made to improve the situation. A long term project launched by Chinese government has carried out to protect the wildlife, orchids are one of the key species in the project. on in situ conservation, the natural reserves of varies kinds have be increased to 2349 , covering 150 million hectares of area, more than 15 per cent of the total territory. Moreover, those natural reserves will cover almost the upper reaches of China's major rivers and areas featuring intact bio-diversity and the richest orchid flora. Particularly, one special orchids nature reserve was set up in Guangxi Province in 2005. About ex situ conservation, the State Forestry Administration of China has set up one ex situ conservation center in Shengzheng, Guangdong Province. Also as one important part of the China's southwest wild biological germplasm resource bank, the orchids seed bank project has been started in 2004. Morover, a reintroduction project of Doritis pulcherrima Lindl. was carrying out in Hainan Island. However, the conservation of the orchids is in fact a complicated problem, not only depending on education and economic development, but also to a large extent on the biological characters of the orchids themselves. It needs a comprehensive study of ecology, population biology, pollination biology, breeding biology and other biological branches. 